\title{
MACROANATOMICAL ASPECTS OF BRACHIAL PLEXUS AND ITS BRANCHES IN THE INDIGENOUS DUCK
}

\author{
J. Alam, M. S. Arifin and M. T. Hussan* \\ Department of Anatomy and Histology, Faculty of Animal Science and Veterinary Medicine, Patuakhali Science \\ and Technology University, Khanpura, Babugonj, Barisal-8210, Bangladesh.
}

\begin{abstract}
The injury to the peripheral nervous system is common clinical problem especially injury to the wing is the most common in birds. The present study aimed to document the detailed features of the morphological structure and the innervations areas of the brachial plexus in indigenous duck (Anas platyrhynchos domesticus). A total of six mature indigenous ducks (three of them were male and three were female) were used in this study. After administering an anesthetic to the birds, the body cavities were opened. The birds were fixed with formaldehyde after draining of the blood. The nerves of the brachial plexus were dissected separately and photographed. The brachial plexus was formed by the union of the ventral branches of $14^{\text {th }}$ and $15^{\text {th }}$ cervical spinal nerve and $1^{\text {st }}, 2^{\text {nd }}$ and $3^{\text {rd }}$ thoracic spinal nerves, which were confirmed by palpation and counting the cervical vertebrae. Present study revealed that few small and large branches originated from brachial plexus and innervated into the specific muscles and their adjacent structure. Five nerve roots formed three nerve trunks in the duck, which constitute the dorsal and ventral cords. The pectoral trunk and median-ulnar nerve originated from ventral cord, while dorsal cord gives axillary nerve continued as a radial nerve into the wing of duck. The axillary nerve innervated into to skin of the dorsal side of the wing and shoulder deltoideous muscles, coracobrachialis muscles and propatagiasis cervical muscles. The radial nerve innervated to the humuro-brachial and triceps muscles, extensor carpi radial and supinator muscles. The ulnar nerve innervated extensor aspect of joint, flexor carpi ulnar muscles and superficial flexor muscle. The median nerve innervated into the median surface of the brachial and metacarpal region, flexor carpi radial muscle, pronator teres muscles, superficial and profound digital flexor muscles. The general macroanatomical shape of the brachial plexus and the distribution of the nerves originating from this plexus displayed some differences from other birds.
\end{abstract}

Keywords: Indigenous duck, innervation, brachial plexus, wings, spinal nerves, birds.

\section{INTRODUCTION}

Currently there is great interest in many different avian species for numerous reasons including, birds serving as companion animals, as models in biological and biomedical research and as sources of high quality protein (McLelland, 1990).Poultry rearing is an integral part of the rural farming communities in Bangladesh (Amber and Mia, 2002; FAO, 1991). Duck rearing is well suited in the coastal and low-land areas and rural duck rearing, owned and managed by women and children, is important for reducing poverty in resource poor smallholder families (Pym et al., 2002). The Smallholder Livestock Development Project in Five Southern Districts is promoting a simple duck production model, in which some people in rural communities act as duck rearers and others as duck vaccinators (Sarkar et al., 2005). The use of animals as experimental models has been recommended in biomedical studies in order to perfect and validate existing procedures, in the development of new materials, and in the understanding of different physiological and anthological processes, as there are no in vitro models able to reproduce completely reproduce the complexity of the human body (Fagundes and Taha, 2004). Animal body is organized with different system and each system has specific function for maintenance of the normal physiology of the animals. Among them, nervous system is the master system of the body and it control and coordinates all other system. Central and peripheral nervous system maintain their activity. The injury to the peripheral nervous system is common clinical problem especially injury to the wing is most common. Sometimes, it may cause death due to proper treatment and wrong treatment for lacking of the knowledge of nerve innervations to the wing of a bird. Anatomic knowledge of neuronal pathways and their landmarks have been used for many regional anesthetic techniques in mammals (Futema et al., 2002). Regional anesthetic techniques provide anesthesia to a restricted portion of the body while leaving physiologic functions and metabolism intact. Brachial plexus nerve block has been reported to produce anesthesia distal to the upper arm in

*Corresponding e-mail address: tufazzal84@gmail.com

Copyright ( 2017 Bangladesh Society for Veterinary Medicine All rights reserved 0390/2017 


\section{J. Alam and others}

humans (Urban and Urquhart, 1994) and distal to the elbow in dogs (Futema et al., 2002). The wing of a bird is innervated with the branches of brachial plexus which is form by union of the ventral rami of specific spinal nerve originated from cervical and thoracic region of the spinal cord. It varies species to species even individual to individual. The knowledge about the nerves that comprise the nervous plexuses and structures innervated by them is important to understand the anatomical, physiological and postural features (Dyce et al., 2010). The anatomy of the brachial plexus has been examined in different vertebrates to determine with general and a detailed anatomical analysis of human brachial plexus has been performed (Fioretto et al., 2003).Comparative anatomy of the formation of the brachial plexus has been studied since the 19th century (Paterson, 1887). It $t$ is a complex anatomical structure, from its origin to the neck and to its final branching in the axillary region (Fazan et al., 2003), and remains one of the most intriguing themes of contemporary anatomy (Shinn et al., 2016). Knowledge on the anatomical characteristics and the variations of this plexus is an important in applied studies, and may make the diagnosis of neuromuscular dysfunctions easier.

To understand a little better the features of design that characterize a mammal organism, we must interpret its structure from a comparative perspective, including the lower tetrapods in the analysis of brachial plexus, even though there are fewer available reports on birds than on mammals. In birds, brachial plexus innervates the musculature of the wing and the trunk as well as the skin and blood vessels of this region of the body (Nickel et al., 1977). The neuroanatomy of avian brachial plexus within peripheral nervous system has been studied chickens (Baumel, 1975), great horned owls (Bubo virginianus) (Moore et al., 1989), cockatiels (Nymphicus hollandicus) (Murphy and Shivaprasad, 2008), red-tailed hawks (Buteo jamaicensis) (Shell et al., 1993), merlin (Falco columbarius) (Cevik-Demirkan, 2014), blue-and-yellow macaws (Araararauna) (AchoaFilho et al., 2014) and blue-fronted parrot (Amazona aestiva) (Silva et al., 2015). However, the anatomy of the brachial plexus and innervation pattern in the duck has not been exclusively investigated. Thus, we have aimed to elucidate the morphological features of the brachial plexus in the indigenous duck and to discuss its similarities and dissimilarities with other avian and vertebrate species.

\section{MATERIALS AND METHODS}

A total of six mature indigenous ducks (three of them were male and three were female) were used in this study. The ducks were purchased from the local market near the Faculty of Animal Science and Veterinary Medicine, Patuakhali Science and Technology University, Babugonj, Barisal. All the ducks were apparently healthy and devoid of any external abnormalities. The live body weights of birds were varied from 1.5 to $2.0 \mathrm{~kg}$. The ducks were euthanized with ketamine hydrochloride and xylazine hydrochloride (Renata) @ 60 and 6mg/kg body weight, respectively. All the ducks were bled to death by giving incision on the right common carotid artery. The dissection was done carefully with simple dissecting instrument. To document the spinal nerves forming the brachial plexus, skin and muscles were dissected, and adipose tissues, mucous substances were removed carefully. The specimens were studied bilaterally. The photographs were taken using a digital camera. The terminology used in this study is compatible with that of the Nomina Anatomica Avium (Baumel et al., 1993).

\section{RESULTS AND DISCUSSION}

The avian brachial plexus has been the subject of several clinical and surgical studies. Plexus components are frequently in traumatic episodes, in local and regional anesthetic procedures, and in studies to determine the functional role of red and white fibers during the flight of the poultry. Based on the literature of chicken brachial plexus (Baumel, 1975; Baumel et al., 1993), anesthetic block techniques of brachial plexus have been studied in chicken (Figueiredo et al., 2008; Cardoza et al., 2009) as well as in the duck (Brenner et al., 2010). Although the comprehensive study of brachial plexus in the duck was still lack. Thus, the present study provided valuable information regarding the origin and distribution of brachial plexus indigenous duck. In the duck, brachial plexus was formed by the union of the ventral branches of last two cervical (C14-15) and first three thoracic (T1-3) spinal nerves (Fig. 1A). The root from the first thoracic spinal nerve has the largest diameter. The root coming 
from the last cervical and second thoracic has nearly equal in diameter. The root from the cervical 14 (C14) was very small in diameter and was united with the root of the last cervical (C15) near the vertebral column. Similarly, a tiny fiber root from the third thoracic spinal nerve merged with the root of the second thoracic spinal nerve (Fig. 1A). The five roots of the plexus united and form three short trunks in which there was an exchange of fibers (Fig. 1B). The first trunk was formed by the anastomosis of the last two cervical (C14-15) spinal nerves. The second trunk was formed only by the first thoracic spinal nerves, while the third trunk was formed by the anastosis of the second and third thoracic cervical spinal nerves (Fig. 1B). The trunks were divided into dorsal and ventral divisions, which combine to form two nerve cords (Fig. 1C). The dorsal cord innervated the extensor muscles and the overlying skin of the wing muscles, whereas branches from the ventral cord innervated the flexor muscles of the wing.

In our study, brachial plexus was formed in the duck by the ventral rami of the C14-15 and T1-3, which is different from the other avian species. For example, in the chicken brachial plexus was reported to originate from last three cervical (C13-15) and first thoracic (T1) (Baumel, 1975). In the ostrich, the brachial plexus originates from the ventral branches of the last cervical and first thoracic spinal nerves (Pospieszny et al., 2009). The brachial plexus of the English sparrow was formed by the three spinal nerves, C11, C12 and C13; no part of C14 joins the plexus (Swinebroad, 1954).In the pigeon, the brachial plexus was formed by the spinal segments 13 to 16, which correspond to the last three cervical and the first thoracic (Franceschi et al., 2009). In the blue-andyellow macaws, nerves originating to form brachial plexus from the intervertebral spaces between the tenth cervical vertebra and the second thoracic vertebra (AchoaFilho et al., 2014). In the blue-fronted parrot, brachial plexus was formed by the ventral braches of the C9 to C11 and T1 to T2 spinal nerves (Silva et al., 2015). In the brachial plexus of merlins, a raptor, two trunks were reported as the accessory brachial plexus and the brachial plexus. Accessory brachial plexus consisted of ventral rami of $\mathrm{C} 10$ and $\mathrm{C} 11$ spinal nerves. The brachial plexus was composed of a rather complex network involving the ventral rami of C11-13, T1 and T2 spinal nerves (Cevik-Demirkan, 2014).In the indigenous duck, the root coming from the first thoracic was the largest in diameter, whereas in the chicken and pigeon, the last cervical nerve was the largest nerve in the brachial plexus (Baumel, 1975;Franceschi et al., 2009). In the present study, three nerve trunks were observed in the duck. Same numbers were observed for the chicken (Baumel, 1975), turkey (Moreira et al., 2005) and domestic pigeon (Franceschi et al., 2009). Different findings were reported in blue-fronted parrot (Silva et al., 2015) and vultures (Moreira et al., 2009), where four trunks were formed from the brachial plexus.

The pectoral trunk and median-ulnar nerve originated from ventral cord, while dorsal cord gives axillary nerve continued as a radial nerve into the wing of duck (Fig. 1C, 1D). Functionally, the plexus was divided into four groups: dorsal and ventral thoracic nerves, and dorsal and ventral brachial nerves. The superficial rhomboideus, profundus rhhomboideus muscles, ventral serratus muscles, and superficial serratus muscles were innervated by the dorsal thoracic nerves. The supracoracoideus and scapulohumeral muscles were innervated by the ventral thoracic nerve and originated the subscapularis nerve. The large pectoral nerve was also originated from the ventral thoracic nerve that innervated the pectoral muscles (Fig. 1C). Longissimus muscles, skin of the dorsal side of the wing and shoulder, deltoideus muscles, coracobrachialis muscles, propatagiasis cervical muscles were innervated by the filaments originated from the dorsal brachial nerves. On the other hand, dorsal brachial nerves gives birth the anconeal and radial nerve which innervate to the anconeal muscles, triceps and humero-brachialis muscles, respectively. At the junction of the elbow, the radial nerve sends branches to the extensor carpi radialis muscles, supinator muscles, abductor digital longus, extensor digital longus, extensor carpi ulnaris, extensor digital communis epicondyle-ulnar muscles and wing. Caudal cutaneous and median-ulnar nerve is the branches of ventral brachial nerve. The median-ulnar nerve gives of branches and innervated into the coracobrachialis and brachial biceps muscles. At the level of elbow joint, medianoulnar nerve were separated into ulnar nerve and median nerve (Fig. 1E). Ulnar nerve innervated the extensor flexor carpi ulnar muscles, superficial digital flexor and small metacarpal flexor muscles (Fig. 1F). The median nerve innervated filaments into elbow joint, brachial and metacarpal region forming cutaneous nerve (Fig. 1F). It also innervated the flexor carpi radial and pronator teres muscle by a musculocutaneous branch, the ventral ulnar metacarpal, superficial and profound digital flexor and small metacarpal muscles. 


\section{J. Alam and others}
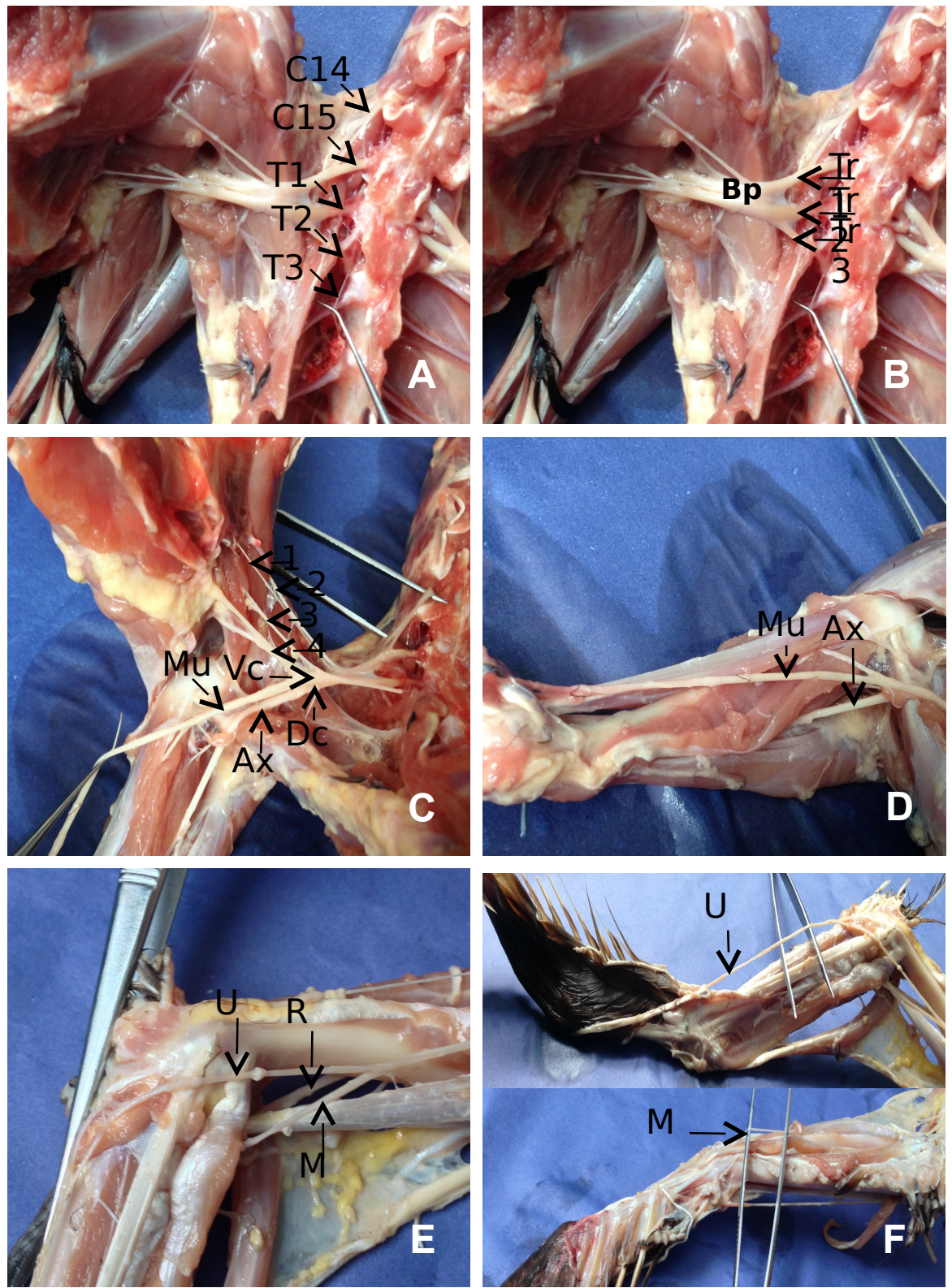

Figure 1. Formation of brachial plexus and its branches in the indigenous duck. A. Brachial plexus was formed by the union of the ventral branches of last two cervical (C14-15) and first three thoracic (T1-3) spinal nerves. B. The five roots of the brachial plexus united and form three short trunks in which there was an exchange of fibers. C. The trunks were divided into dorsal and ventral divisions, which combine to form two nerve cords. The pectoral trunk and medianoulnar $(\mathrm{Mu})$ nerve originated from ventral cord $(\mathrm{Vc})$, while dorsal cord (Dc) gives axillary (Ax) nerve continued as a radial nerve into the wing. D. Shows the medinoulnar nerve and axillay nerve at the proximal end of the humerus. E. Shows the medial, ulnar and axillay nerve at the distal end of the humerus. F. Shows the ulnar $(\mathrm{U})$ nerve, radial $(\mathrm{R})$ nerve and median $(\mathrm{M})$ nerve at the forearm level. $\mathrm{Bp}=$ Brachial plexus; $\mathrm{C} 14, \mathrm{C} 15=$ Cervical spinal nerve 14, 15; T1, T2, T3= Thoracic spinal nerve 1-3; $\operatorname{Tr} 1, \operatorname{Tr} 2, \operatorname{Tr} 3=\operatorname{Trunk} 1,2,3 ; 1 .=$ Nerve (n.) to supracoracoideus; $2 .=\mathrm{n}$. to sternocoracoideus; $3 .=\mathrm{n}$. to subcoracoideus; $4 .=$ Pectoral trunk. 
Same as to other avian species, the terminal branches from the brachial plexus to the wing are the radial, median and ulnar nerve. The large pectoral nerve was originated from the ventral thoracic nerve that innervated the pectoral muscles, was as like as to other species of birds except in ostrich. Pospieszny et al. (2009) concluded that the pectoral nerve was not present in the ostrich, partly because of its poor size of pectoral muscle. Similar to our findings, in general, it was previously reported that on the internal surface of the elbow joint the medianoulnar nerve divided into the ulnar nerve which was located laterally and the median nerve located medially in birds (Baumel et al., 1993; Pospieszny et al., 2009). In the duck, radial nerve originated from axillary nerve a branch of dorsal brachial nerves which continued up to digit as single branch as in other birds. But this nerve originates from the dorsal fasciculus in ostriches, and it divides into the superficial branch and deep branch (Pospieszny et al., 2009).Unlike the spinal cord of mammals, the spinal cord of birds extends along the whole length of the vertebral canal, including the coccygeal region, and its length is equal to the whole vertebral column and decreases in diameter caudally. The segmentation of the spinal cord is the same as in mammals. Two intumescences- cervical and lumbar are observed in birds. The brachial plexus formed from the cervical intumescences and supplies to the wing. In domestic mammals such as cattle, horse and dog the brachial plexus formed from ventral branches of the last three cervical and first and second thoracic spinal nerves (Baumel, 1975). In the human and nonhuman primates, brachial plexus formed last four cervical (C5-C8) and first thoracic spinal nerves (Ken, 1918; Krechowiecki et al., 1972). In the painted turtles, brachial plexus formed by the C6-8 and first thoracic spinal nerves (Wyneken, 2003), whereas in crocodiles it is composed of $7^{\text {th }}$ to $11^{\text {th }}$ spinal nerves (Meers, 2003). In the snake and limbless lizards, lack in brachial plexus.

\section{CONCLUSION}

The roots of the brachial plexus of indigenous duck were originated from the ventral branches of last two cervical and first three thoracic spinal nerves. The ventral branches of $15^{\text {th }}$ cervical and $1^{\text {st }}$ and $2^{\text {nd }}$ thoracic spinal nerves were the major contributor in formation of brachial plexus. The plexus of indigenous duck was made up several branches that were distributed to the intrinsic, extrinsic and cutaneous muscles of the wing. The results obtained in this study contribute to applied research, serving as a basis for clinical and surgical procedures that may use this species as an experimental model, and provide information for the comparative anatomy of other avian species. In a nutshell, the data generated from here can provide knowledge of the anatomical landmarks for the location of the brachial plexus and can help to determine accurate and reliable techniques of catheter placement for local or regional anesthesia in the duck.

\section{REFERENCES}

1. AchoaFilho K, Rodrigues MN, da Fonseca ET, Leandro RM, Pasqualetti BP and Miglino MA (2014). Origin, distribution, and insertion of the brachial plexus nerves in Blue-and-yellow Macaws (Ara ararauna, Linnaeus, 1758) 27 (3). http://dx.doi.org/10.5007/2175-7925.2014v27n3p157

2. Amber AJ and Mia AS (2002). The potential for adopting the model for ducks in Southern Bangladesh. Proceedings of International Network for poultry Development, on 20-24, October, pp. 1-4.

3. Baumel JJ (1975). Aves nervous system. In: Getty, R.(Ed), fifth ed. In: Sisson and Grossman's. The Anatomy of the Domestic Animals Vol. 2.

4. Baumel JJ, King AS, Breazile JE, Evans HE and Vanden Berge JC (1993). Nomina Anatomica Avium. Cambridge, MA: Nuttall Ornithological Club no.23.

5. Brenner DJ, Larsen RS, Dickinson PJ, Wack RF, Williams DC and Pascoe PJ (2010). Development of an avian brachial plexus nerve block technique for perioperative analgesia in mallard ducks (Anas platyrhynchos). Journal of Avian Medicine \& Surgery 24: 24-34.

6. Cardoza LB, Almeida RM, Fuiza LC and Galera PD (2009). Brachial plexus blockade in chickens with $0.75 \%$ ropivacaine. Veterinary Anaesthesia and Analgesia 36: 396-400.

7. Cevik-Demirkan A (2014). Anatomical structure of the brachial plexus in the merlin (Falco columbarius). Anatomia Histologia Embryologia 43: 31-35.

8. Dyce KM, Sack WO and Wensing CJG (2009). Textbook of Veterinary Anatomy, $2^{\text {nd }}$ edn. London, Philadelphia, PA: W.B. Saunders Co.

9. Fagundes, DJ and Taha MO (2004). Animal disease model: choice's criteria and current animal's specimens. Acta Cirurgica Brasileira 19. http://dx.doi.org/10.1590/S0102-86502004000100010

10. FAO (1991). Statistics on livestock population, Asian Livestock, September, pp.107

11. Fazan VPS, Amadeu ADS, Caleffi AL and Rodrigues FOA (2003). Brachial plexus variations in its formation and main branches. Acta Cirúrgica Brasileira 18: 14-18. 


\section{J. Alam and others}

12. Figueiredo JP, Cruz ML, Mendes GM, Marucio RL, Ricco CH and Campagonol D (2008). Assessment of brachial plexus blockade in chickens by an axillary approach. Veterinary Anaesthesia and Analgesia 35: 511-518.

13. Fioretto ET Souza CMF, Guidi WML, RR Sauza and Ribeiro AACM (2003). Gross Anatomic organization of the capybara's (Hydrochaeries hydrochaeris) brachial plexus. Journal of Anatomy Histology and Embryology 32: 169174.

14. Franceschi RC, Souza DAS, Provenci M and Martinez-Pereira MA (2009). Study of innervation of the thoracic limb of Columba livia. Brazilian Journal of Veterinary Research and Animal Science 46: 507-514

15. Futema F, Fantoni DT, Auler JOC Jr, Cotorpassi SRG, Acaui A and Stopiglia AJ (2002). A new brachial plexus block technique in dogs. Veterinary Anaesthesia and Analgesia, 29(3): 133-139.

16. Ken AT (1918). The brachial plexus of nerves in man, the variations in its formation and branches. The American Journal of Anatomy 23: 285-395.

17. Krechowiecki A, Goscicka D and Samulak S (1972). The lumbosacral plexus and lumbar enlargement in Macaca mulatta. Folia Morphologica 31: 11-19.

18. McLelland J (1990). A colored atlas of avian anatomy. London, England: Wolfe publishing LTD, pp.37.

19. Meers MB (2003). Crocodylian forelimb musculature and its relevance to archosauria. The Anatomical Record 274A: 891-916.

20. Moore MP, Stauber E and Thomas N, (1989). Avulsion of the brachial plexus in a great horned owl (Bubo virginianus). Journal of Raptor Research 23: 3-9.

21. Moreira PRR, de Souza WM, de Souza NTM and Carvalho RG (2009). The arrangement of configured of nerves of brachial plexus in vulture (Coragyps atratus foetens - Linnaeus, 1758) Brazilian Journal of Veterinary Research and Animal Science 46: 144-151.

22. Moreira PRR, Souza WM, Souza NTM, Carvalho RG, Custodio AA (2005). The arrangement of configured of nerves of brachial plexus in the turkey (Meleagris gallopavo-Linnaeus, 1758). SPARS Vet Jaboticabal 21: 296302.

23. Murphy BG and Shivaprasad HL (2008). Ganglioneuroma of the brachial plexus in two cockatiels (Nymphicus hollandicus). Veterinary Pathology 45: 690-692.

24. Nickel R, Schummer A and Seiferle E (1977). Peripheral nervous system. In: Nickel R, Schummer R, Seiferle E (Eds). Anatomy of the domestic birds. Berlin, Parey, pp 131-139.

25. Paterson AM (1887). The limb plexuses of mammals. Journal of Anatomy and Physiology 21: 611-634.

26. Pospieszny N, Pachulska P, Pazdzior K and Wustinger J (2009). Nerves of thoracic limb of the ostrich (Struthio camelus L.) Electronic Journal of Polish Agricultural Universities 12: 1-5.

27. Pym RAE., Lanada EB and Morbos EY (2002). Case studies of family poultry Development. Second INFPDFAO, Electronic conference, May 13-July 5

28. Sarkar K, Mustafa G and Bell JG (2005). New approaches-from a model to learning approach (reference to Bangladesh Poultry Model). Tirath, SS. (2001). Duck health care. www.duckhealth.com

29. Shell L, Richards M and Saunders (1993). Brachial plexus injury in two red-tailed hawks (Buteo jamaicensis). Journal of Wildlife Diseases 29:177-179.

30. Shinn HK, Kim BG, Jung JK, Kwon HU, Yang C and Won J (2016). Prolonged hemidiaphragmatic paresis following continuous interscalene brachial plexus block: A case report. Medicine (Baltimore) 95: 1-5.

31. Silva RMN, Figueiredo PO and Santana MI (2015). Development and distribution of the brachial plexus in bluefronted parrot (Amazona aestiva, Linnaeus, 1758). Ciencia Animal Brasilia 16. http://dx.doi.org/10.1590/1089$6891 v 16 i 34117$.

32. Swinebroad J (1954). A Comparative study of the wing myology of certain passerines. The American Midland Naturalist Journal 51: 488-514.

33. Urban MK and Urquhart B (1994). Evaluation of brachial plexus anesthesia for upper extremity surgery. Regional Anesthesia 19: 175-82.

34. Wyneken J (2003). The external morphology, musculoskeletal system, and neuroanatomy of sea turtles. In: Lutz PL,(Ed.). The biology of sea turtles, volume 2. In: CRC Marine Biology Series-4, pp39-77. 